\title{
The Contribution of Lake-Effect Snow to Annual Snowfall Totals in the Vicinity of Lakes Erie, Michigan, and Ontario
}

\author{
Erin A. Jones ${ }^{1}$, Carrie E. Lang ${ }^{2}$ and Neil F. Laird ${ }^{3 *}$
}

${ }^{1}$ Department of Earth Sciences, Millersville University, Millersville, PA, United States, ${ }^{2}$ Departments of Mathematics and Geography, State University of New York Geneseo, Geneseo, NY, United States, ${ }^{3}$ Department of Geoscience, Hobart and William Smith Colleges, Geneva, NY, United States

OPEN ACCESS

Edited by:

Adam Burnett,

Colgate University, United States

Reviewed by:

Andrew Ellis,

Virginia Tech, United States

Zachary Suriano,

University of Nebraska Omaha,

United States

Chris Karmosky

SUNY Oneonta, United States

*Correspondence:

Neil F. Laird

laird@hws.edu

Specialty section:

This article was submitted to

Water and Climate,

a section of the journal

Frontiers in Water

Received: 25 September 2021

Accepted: 02 February 2022

Published: 04 March 2022

Citation:

Jones EA, Lang CE and Laird NF (2022) The Contribution of Lake-Effect Snow to Annual Snowfall Totals in the

Vicinity of Lakes Erie, Michigan, and

Ontario. Front. Water 4:782910.

doi: 10.3389/frwa.2022.782910
In the Great Lakes region, total cold-season snowfall consists of contributions from both lake-effect systems (LES) and non-LES snow events. To enhance understanding of the regional hydroclimatology, this research examined these separate contributions with a focus on the cold seasons (October-March) of 2009/2010, a time period with the number of LES days substantially less than the mean, and 2012/2013, a time period with the number of LES days notably greater than the mean, for the regions surrounding Lakes Erie, Michigan, and Ontario. In general, LES snowfall exhibited a maximum contribution in near-shoreline areas surrounding each lake while non-LES snowfall tended to provide a more widespread distribution throughout the entire study regions with maxima often located in regions of elevated terrain. The percent contribution for LES snowfall to the seasonal snowfall varied spatially near each lake with localized maxima and ranged in magnitudes from $10 \%$ to over $70 \%$. Although total LES snowfall amounts tended to be greater during the cold season with the larger number of LES days, the percent of LES snowfall contributing to the total cold-season snowfall was not directly dependent on the number of LES days. The LES snowfall contributions to seasonal totals were found to be generally larger for Lakes Erie and Ontario during the cold season with a greater number of LES days; however, LES contributions were similar or smaller for areas in the vicinity of Lake Michigan during the cold season with a smaller number of LES days.

Keywords: snowfall, Great Lakes, lake-effect, mesoscale, climatology

\section{INTRODUCTION}

A large variety of agriculture, transportation, and tourism operations are directly linked to the large freshwater lakes and the weather systems that occur within the Great Lakes region of North America. Cold-season lake-effect system (LES) snowfall is a phenomenon that greatly affects both the weather and climate in the vicinity of each lake and occurs when a cold airmass is modified as it passes over one or more of the Great Lakes. The sensible and latent heat fluxes from the surface of the lake lead to instability within the atmospheric boundary layer, typically below $1-3 \mathrm{~km}$ during LES situations. This instability often leads to the development of LES clouds over and downwind of the Great Lakes creating a greater possibility for precipitation and substantial amounts of snowfall (e.g., Jiusto and Kaplan, 1972). In addition to many favorable benefits to the region, these substantial snowfalls can 
lead to significant societal impacts, such as traffic accidents, property damage, and disrupted air travel (e.g., Schmidlin, 1993; Burow and Atkinson, 2019).

Numerous studies have examined the spatial distribution of total cold-season snowfall to infer which areas near the Great Lakes have the greatest LES snowfall amounts (e.g., Muller, 1966; Eichenlaub, 1970; Jiusto and Kaplan, 1972; Strommen and Harman, 1978; Norton and Bolsenga, 1993; Scott and Huff, 1996). Estimating the proportion that LES snowfall contributes to the cold-season snowfall for different areas is a complex task and has been approached using a variety of methods (e.g., Eichenlaub, 1970; Wilson, 1977; Braham and Dungey, 1984, 1995; Kelly, 1986; Scott and Huff, 1996; Yeager et al., 2013; Suriano et al., 2019; Ellis et al., 2020; Hartnett, 2021; Suriano and Wortman, 2021). However, this remains a challenge, especially for studies examining the long-term trends of snowfall within the Great Lakes region (e.g., Burnett et al., 2003; Ellis and Johnson, 2004; Kunkel et al., 2009; Bard and Kristovich, 2012; Hartnett et al., 2014; Clark et al., 2016, 2018; Suriano and Leathers, 2017; Baijnath-Rodino et al., 2018; Ellis et al., 2020).

Many past studies have primarily used one of three approaches for determining LES contribution to total coldseason snowfall. These include: (1) comparing measured total cold-season snowfall at locations nearer the lake (i.e., in snowbelt areas) to locations further inland from the lake (e.g., Scott and Huff, 1996), (2) comparing total cold-season snowfall measured at locations upwind of the lake to downwind locations (e.g., Braham and Dungey, 1984), or (3) using synoptic pattern classification to infer LES occurrence and comparing snowfall during LES synoptic patterns to snowfall that occurred during non-LES synoptic patterns (e.g., Eichenlaub, 1970; Suriano and Leathers, 2017; Suriano, 2019; Suriano and Wortman, 2021). A recent study by Ellis et al. (2020) utilized synoptic pattern classification in combination with comparing surface airmass attributes upwind and downwind of different lakes to identify likely LES days and investigate the long-term trends in both LES occurrence and snowfall. Each of these approaches used in past studies infer LES snowfall without knowledge of the occurrence of observed mesoscale LES cloud or precipitation patterns. For example, Suriano and Leathers (2017), Suriano (2019), and Suriano and Wortman (2021) acknowledge that synoptic patterns classified as LES are not directly linked with observed LES precipitation or mesoscale LES processes, but rather identify days where environmental conditions were favorable for possible LES development.

Using these varied approaches, past studies have arrived at differing conclusions about the LES contribution to total cold-season snowfall. For example, Dewey (1970) concluded that some areas in the LES snowbelt east of Lake Michigan received 200\% more snow than further inland Michigan stations. Eichenlaub (1970) estimated that at least $30 \%$ of seasonal snowfall in this same snowbelt region came from lake-atmospheric interactions. Strommen and Harman (1978) concluded that LES snowfall in this same area contributed to a $50-300 \%$ increase in mean cold-season snow totals. Braham and Dungey (1984) estimated the effect of Lake Michigan on total cold-season snowfall was an increase of $10 \%$ for the southern Wisconsin shoreline region and an increase of $60 \%$ for the snowbelt area east of Lake Michigan. Analyses by Clark et al. (2016, 2018) suggested that LES led to an increase of cold-season snowfall between 170 and 315\% when comparing areas east and west of Lake Michigan. Wilson (1977) found LES led to precipitation increases of $\sim 25 \%$ near Lake Ontario, and over $50 \%$ in regions of higher terrain east of the lake, such as the Tug Hill Plateau. Suriano and Wortman (2021) found that snowfall that occurred in the Lakes Erie and Ontario regions comprised $\sim 48 \%$ of total cold-season snowfall. When considering snowfall throughout the Great Lakes region, Scott and Huff (1996) estimated increases of winter precipitation from LES in areas near the downwind shorelines to have maxima ranging from 35 to $100 \%$, with much variability in the spatial distribution.

The authors are aware of only a few previous studies that have used a combination of radar, satellite, and surface weather observations to identify LES occurrences and provide information about the contribution of LES snowfall to seasonal totals. Veals and Steenburgh (2015) used radar and assimilated snowfall data to find that LES days accounted for $61-76 \%$ of the mean cool-season snowfall and $24-37 \%$ of the mean cool-season liquid precipitation for a region surrounding the KTYX National Weather Service radar located near Montague, New York on the Tug Hill Plateau east of Lake Ontario. In a study examining a variety of snowstorm types impacting a region east and southeast of Lake Ontario, Hartnett (2021) found that LES snowstorms accounted for $\sim 39 \%$ of the total seasonal snowfall.

The current research provides new insight and knowledge of the hydroclimatological contribution of LES snowfall to cold-season snowfall totals using information of observed LES occurrences determined from satellite imagery and highresolution assimilated snowfall data in the vicinity of Lakes Erie, Michigan, and Ontario for two cold seasons. The application of these results thereby provide an enhanced understanding of LES snowfall contributions to seasonal snowfall totals, how those contributions differ spatially in the vicinity of three different lakes, and whether the frequency of LES days in a winter is likely to influence the LES snowfall contributions.

\section{DATA AND METHODS}

The study focuses on two cold seasons with the aim of comparing LES snowfall contribution for a cold season with the number of LES days substantially less than the mean to a cold season with the number of LES days notably greater than the mean for each lake. The two cold seasons were determined using a daily LES database created by Laird et al. (2017). Using Geostationary Operational Environmental Satellite (GOES) visible imagery, Laird et al. (2017) documented when LES clouds were present over each of the Great Lakes for each day during the 17 cold-seasons (October-March) from 1997/1998 through 2013/2014. The mean number of LES days per cold season for Lakes Erie, Michigan, and Ontario were $50.8,77.9$, and 62.0, respectively. Examination of the daily LES database was used to identify the cold season of 2009/2010 as 
TABLE 1 | Ranking of cold seasons based on the number of LES days for Lakes Erie, Michigan, and Ontario from the 17 cold-season database of Laird et al. (2017).

\begin{tabular}{llll}
\hline Rank & Erie LES & Michigan LES & Ontario LES \\
\hline 1 & $2004-2005$ & $2013-2014$ & $2013-2014$ \\
2 & $1999-2000$ & $2002-2003$ & $2008-2009$ \\
3 & $2012-2013$ & $2008-2009$ & $2000-2001$ \\
4 & $2005-2006$ & $2012-2013$ & $2012-2013$ \\
5 & $1998-1999$ & $2000-2001$ & $2004-2005$ \\
6 & $2008-2009$ & $1999-2000$ & $2003-2004$ \\
7 & $2000-2001$ & $2005-2006$ & $2002-2003$ \\
8 & $2006-2007$ & $1998-1999$ & $2010-2011$ \\
9 & $1997-1998$ & $2003-2004$ & $1998-1999$ \\
10 & $2003-2004$ & $2006-2007$ & $2006-2007$ \\
11 & $2013-2014$ & $2007-2008$ & $2005-2006$ \\
12 & $2001-2002$ & $2010-2011$ & $1999-2000$ \\
13 & $2010-2011$ & $2004-2005$ & $2007-2008$ \\
14 & $2011-2012$ & $1997-1998$ & $2001-2002$ \\
15 & $2007-2008$ & $2001-2002$ & $1997-1998$ \\
16 & $2002-2003$ & $2009-2010$ & $2009-2010$ \\
17 & $2009-2010$ & $2011-2012$ & $2011-2012$ \\
\hline & & &
\end{tabular}

Grey highlighted cold seasons are those used in this study.

one of the least active in terms of LES with 32, 52, and 42 LES days over Lakes Erie, Michigan, and Ontario, respectively. The 2012/2013 cold season was identified as an active LES time period with 63, 88, and 70 LES days over Lakes Erie, Michigan, and Ontario, respectively.

The ranking of cold seasons based on the number of LES days for the 17 cold seasons from Laird et al. (2017) is shown in Table 1. The annual variation and distribution attributes of the number of LES days for the 17 cold seasons in each lake region is shown in Figure 1. The 2009/2010 cold season was the only cold season in the lowest quartile of LES days for each of the three lake regions and the 2012/2013 cold season was the only cold season in the highest quartile of LES days for each of the three lake regions. Identifying a cold season with all three lakes having the number of LES days substantially less than the mean and a second cold season with all three lakes having the number of LES days notably greater than the mean allowed for a more directed examination of whether the LES snowfall contribution to total seasonal snowfall differed based on the number of LES days by attempting to limit influence from variation in frequency, strength, and track of synoptic systems over different lakes. An examination of intraseasonal and interannual variations of LES snowfall contribution to monthly snowfall totals across multiple decades, different lake regions, and differing regional synoptic and mesoscale atmospheric conditions is beyond the scope of the current study and is an area of future investigation.

To determine the LES contribution to total cold-season snowfall, days in the two cold seasons were sorted into two categories based on the cold-season LES database described by Laird et al. (2017). Each day was designated as a day with LES observed over the specified lake or a day with no LES observed over the specified lake. The single designation of snowfall, as LES or non-LES, for each day does lead to some uncertainty of the snowfall totals in each category since a small number of days each cold season may have both non-LES and LES snowfall. For example, this approach would not capture LES snowfall that may have occurred in the vicinity of a cyclone passing over a specific lake where widespread synoptic cloud cover and precipitation may have occurred with embedded LES snowfall (i.e., a lakeenhanced snowfall situation) (e.g., Owens et al., 2017). With the synoptic overcast cloud cover inhibiting the ability to observe the presence of LES clouds, this type of situation would be classified as a non-LES snowfall day and lead to an underestimate of LES snowfall. Additionally, if LES snowfall occurred only during nighttime periods, the methodology from Laird et al. (2017) of using GOES visible satellite imagery to identify LES days would lead to an underestimate of LES snowfall. Alternatively, a day that had a transition from non-LES snowfall to LES snowfall during the time of day when LES clouds were identified from the GOES visible imagery would result in this day being classified as a LES snowfall day and lead to an overestimate of LES snowfall.

To examine the amount of snowfall in each geographic area, SNOw Data Assimilation System (SNODAS) solid precipitation (i.e., snowfall) data was analyzed using Geographic Information Systems (GIS). SNODAS assimilates satellite, airborne, and ground-based observations into a snow mass and energy balance model to create an estimation of snow water equivalent and snow pack thickness at $1-\mathrm{km}$ horizontal resolution over the continental United States (Barrett, 2003). Daily gridded data, as used in this study, are available from the National Weather Service's National Operational Hydrologic Remote Sensing Center (NOHRSC) from September 2003 to the present. These data are available for only the continental United States for most of the archive, therefore our analyses and investigation focused on Lakes Erie, Michigan, and Ontario-Great Lakes with extensive shoreline regions within the continental United States. SNODAS snowfall data have been used for several past LES snowfall studies (e.g., Veals and Steenburgh, 2015; Lang et al., 2018) and are archived as liquid water equivalent (LWE) amounts. Total LWE daily snowfall for LES days and non-LES days, as well as summed across each cold season, were used to determine the contribution to the total cold-season snowfall in areas surrounding Lakes Erie, Michigan, and Ontario.

\section{RESULTS}

\section{Comparing Total Cold-Season Snowfall Lake Erie}

The total cold-season snowfall for both winters in areas to the west and south of Lake Erie were very similar (Figures 2A,D). Generally, areas to the west and southwest of Lake Erie had LWE snowfall amounts of $4.0-19.3 \mathrm{~cm}$. In both cold seasons, areas to the southeast of Lake Erie had larger snowfall amounts with LWE totals in the range of $19.3-34.6 \mathrm{~cm}$. The maximum snowfall occurred in counties of northwestern Pennsylvania and southwestern New York where elevation rises quickly from lake level to a height of $430 \mathrm{~m}$ within about $10 \mathrm{~km}$ from the lake shoreline. The cold-season snowfall patterns and totals in this area for the two cold seasons studied are consistent with findings 


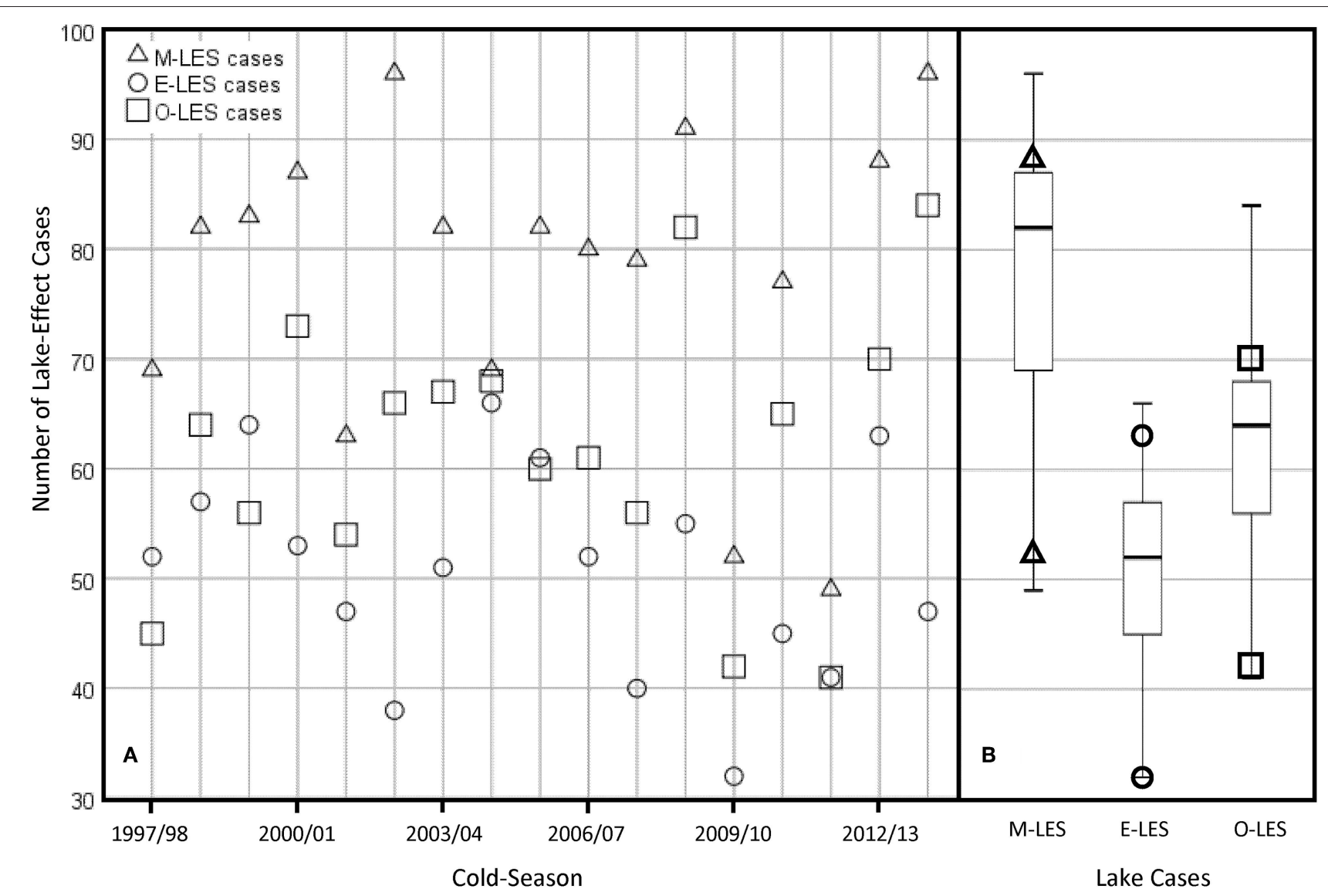

FIGURE 1 | The annual variation (A) and distribution attributes (B) of the number of LES days for the 17 cold seasons from Laird et al. (2017) in the Lake Michigan (M-LES; triangles), Lake Erie (E-LES; circles), and Lake Ontario (O-LES; squares) regions. The number of LES days for cold seasons of 2009/2010 and 2012/2013 are identified on the box-plots in panel (B) using symbols within the lowest and highest quartiles, respectively.

from past studies reporting on mean climatological cold-season (O-M) or winter (DJF) snowfall distribution across the Great Lakes region. For example, Scott and Huff (1996) showed that the 30-year mean LWE winter snowfall for the region southeast of Lake Erie was $22.5-30.0 \mathrm{~cm}$. Norton and Bolsenga (1993) found the 30-year mean annual snowfall depth for this Lake Erie region ranged from 100 to $400 \mathrm{~cm}$.

\section{Lake Michigan}

In both 2009/2010 and 2012/2013 cold seasons, the Upper Peninsula (UP) of Michigan and the region east of Lake Michigan (in particular the northern half of the lake) received the largest amounts of snowfall (Figures 2B,E). During 2009/2010, seasonal LWE snowfall totals in the UP region ranged from about 9.1 to $34.6 \mathrm{~cm}$. LWE snowfall east and west of Lake Michigan had values in the range of $14.2-24.4 \mathrm{~cm}$ and $4.0-19.3 \mathrm{~cm}$, respectively. In the 2012/2013 cold season, total LWE snowfall amounts in the UP of Michigan were notably larger with values ranging from about 24.4 to $50.0 \mathrm{~cm}$. Total cold-season LWE snowfall amounts east and west of Lake Michigan were also greater than observed during the 2009/2010 cold season with values between $14.2-39.7 \mathrm{~cm}$ and $14.2-24.4 \mathrm{~cm}$, respectively. Long-term mean snowfall for this region from Scott and Huff (1996) showed that LWE winter snowfall north and east of Lake Michigan were $12.5-17.5 \mathrm{~cm}$ and totals west of Lake Michigan were $7.5-10.0 \mathrm{~cm}$. Norton and Bolsenga (1993) found the 30-year mean annual snowfall depth for these regions near Lake Michigan ranged from a maximum of about $400 \mathrm{~cm}$ in Upper Michigan to upwards of $300-350 \mathrm{~cm}$ east of Lake Michigan and $\sim 100-150 \mathrm{~cm}$ west of Lake Michigan.

\section{Lake Ontario}

Total snowfall was similar during both cold seasons for areas south of Lake Ontario; however, the areas east of Lake Ontario had noteworthy differences between 2009/2010 and 2012/2013 (Figures 2C,F). In 2012/2013, maxima of total LWE snowfall occurred over the Tug Hill Plateau and the Adirondack Mountain regions east of Lake Ontario. Totals in the highest elevations of the Tug Hill Plateau (i.e., $512 \mathrm{~m}$ above lake level) were 50.0-55.1 cm. During 2009/2010, the largest total LWE snowfall amounts occurred in the Catskill Mountain and Southern Adirondack Mountain regions that are east and southeast of Lake Ontario. These totals ranged from about 24.4 to $44.8 \mathrm{~cm}$ with slightly larger amounts occurring in the Catskill Mountain 


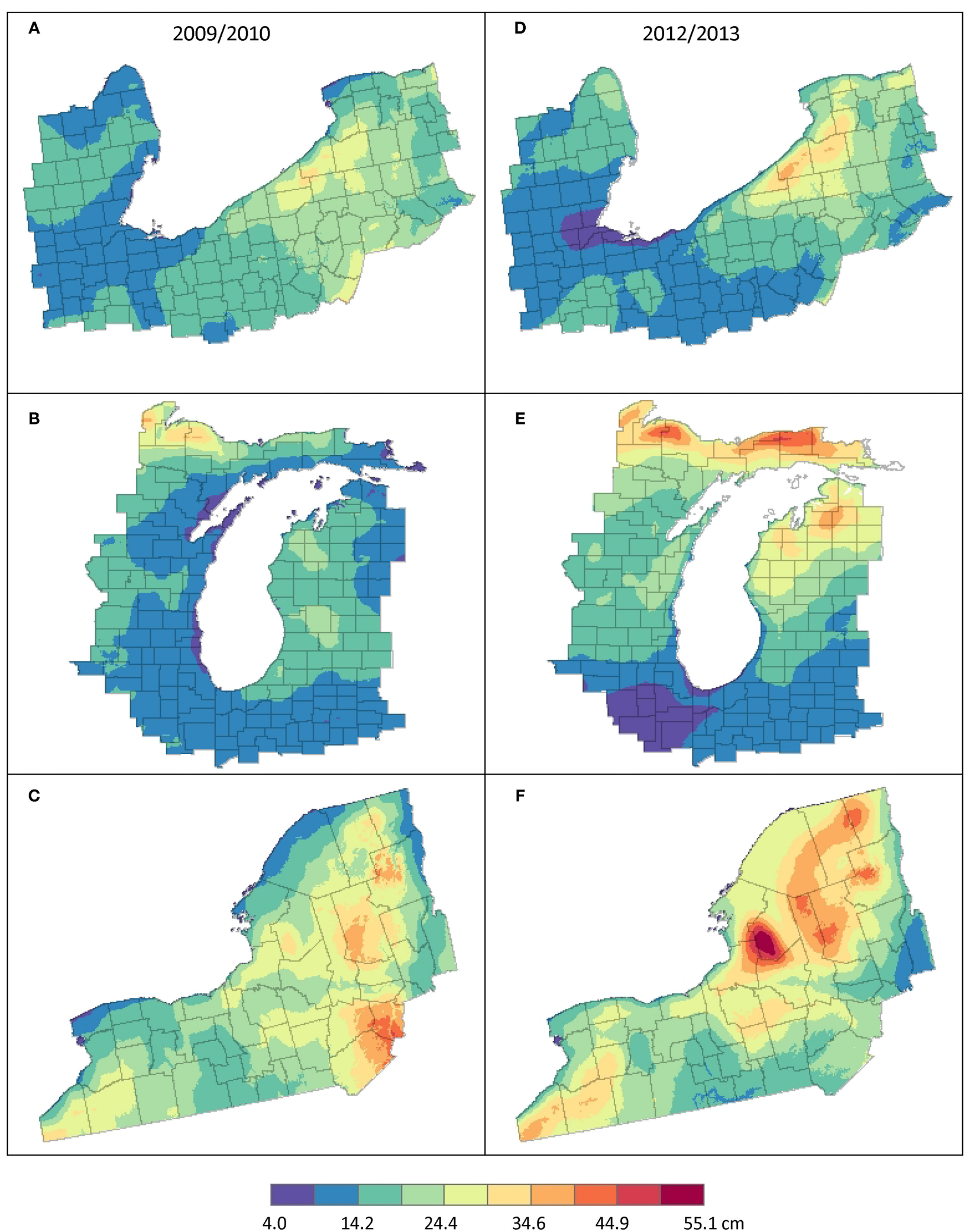

FIGURE 2 | The total cold-season LWE snowfall (cm) during the 2009/2010 season for the (A) Lake Erie, (B) Lake Michigan, and (C) Lake Ontario regions and during the 2012/2013 season for the (D) Lake Erie, (E) Lake Michigan, and (F) Lake Ontario regions. 
region. The total LWE snowfall amounts south of Lake Ontario ranged from 9.1 to $29.5 \mathrm{~cm}$ during both cold seasons. Norton and Bolsenga (1993) found the 30-year mean annual snowfall depth had maxima in similar areas of the Tug Hill Plateau, Adirondack Mountains, and Catskill Mountains east of Lake Ontario. They found long-term mean snowfall depths in these regions ranging from 200 to $>400 \mathrm{~cm}$. Scott and Huff (1996) showed that 30-year mean LWE winter snowfall for the regions east and southeast of Lake Ontario had totals of $22.5-32.5 \mathrm{~cm}$ while areas south of Lake Ontario had winter totals of $15.0-20.0 \mathrm{~cm}$.

\section{Comparing LES and Non-LES Snowfall Lake Erie}

The spatial patterns of LWE snowfall from Lake Erie LES days during both cold seasons (Figures 3A,C) clearly denote the primary LES snow region positioned near the southeastern shoreline. This region of accumulated cold-season LES snowfall stretches westward from southeast of Buffalo, NY to Erie, PA. This region is typically located downwind of the lake during LES situations and has substantial elevation rise inland from the lake shore. During 2009/2010, most of the LES snow region received LWE totals of $3.8-10.3 \mathrm{~cm}$. The 2012/2013 cold season had similar LWE snowfall totals of $3.8-13.6 \mathrm{~cm}$ in this region. Small cold-season LES snowfall amounts $(<3.8 \mathrm{~cm})$ occurred to the west and southwest of the lake.

The LWE snowfall spatial patterns from non-LES days in the vicinity of Lake Erie that occurred during both cold seasons showed larger totals to the southeast of Lake Erie (Figures 3B,D), as well as larger accumulated snowfall within all counties in the study region. In the 2009/2010 cold season, maximum snowfall accumulations from non-LES days were slightly $>20.2 \mathrm{~cm}$. Areas to the west and southwest of the lake received amounts ranging from 7.1 to $16.9 \mathrm{~cm}$. For the 2012/2013 cold season, the maximum was located near the lake with a value near $23.4 \mathrm{~cm}$. Snowfall totals outside of the region of largest non-LES snowfall were generally less than non-LES snowfall during 2009/2010 and ranged from 3.8 to $13.6 \mathrm{~cm}$.

While the location of the larger non-LES snowfall has some similarity to the LES snowfall region, the larger snowfall amounts accumulated across non-LES days cover a more expansive area. The higher terrain and steep rise above lake level of near-shoreline areas to the southeast of Lake Erie clearly have an influence on snowfall amounts during both LES and non-LES days. The analyses shown in Figure 3 suggest that studies that have only examined total cold-season snowfall to infer the contribution of LES snowfall without considering information of observed LES occurrences or variation of terrain have likely overestimated the percentage of LES snowfall for this region and perhaps other regions where substantial elevated terrain exists in near-shore regions.

\section{Lake Michigan}

The spatial distributions of LES snowfall for the two cold seasons are similar with the largest cold-season totals located in the UP of Michigan and east of Lake Michigan (Figures 4A,C).
The large snowfall totals in the UP of Michigan on Lake Michigan LES days likely resulted from coincidental LES activity occurring in association with Lake Superior. Cold-season LES snowfall totals east of Lake Michigan ranged from $7.1 \mathrm{~cm}$ in the region southeast of the lake to 13.6 and $16.9 \mathrm{~cm}$ northeast of the lake during the cold seasons of 2009/2010 and 2012/2013, respectively. LES snowfall totals west of Lake Michigan were generally $<3.3$ and $7.1 \mathrm{~cm}$ during 2009/2010 and 2012/2013, respectively.

The seasonal snowfall totals from non-LES days were more evenly distributed over regions east and west of Lake Michigan for both cold seasons (Figures 4B,D). For both cold seasons the patterns suggest that the track of extratropical cyclones through the Great Lakes region, as well as elevated terrain in the UP of Michigan and the northern portion of Lower Michigan, may have contributed to the location of larger snowfall totals from non-LES days. During the cold season of 2009/2010, maximum non-LES snowfall totals $(16.9 \mathrm{~cm})$ occurred over central Wisconsin and near the Porcupine Mountains in the UP of Michigan. The maximum non-LES snowfall totals in the cold-season of $2012 / 2013(30.0 \mathrm{~cm})$ also occurred near the Porcupine Mountains in the UP of Michigan with LWE snowfall values $>13.6 \mathrm{~cm}$ extending across northeastern Wisconsin, the UP of Michigan, and the northern portion of Lower Michigan.

\section{Lake Ontario}

In both the active and less active LES cold seasons, the region to the east of Lake Ontario received the largest amounts of snowfall from LES days. For 2009/2010, LES amounts east of Lake Ontario ranged from 3.3 to $10.3 \mathrm{~cm}$ (Figure 5A). The LES snowfall totals east of Lake Ontario during the 2012/2013 cold season were greater and ranged between 3.3 and $16.9 \mathrm{~cm}$ (Figure 5C). During both cold seasons the maximum LES snowfall occurred over the Tug Hill Plateau with larger values extending eastward into the central Adirondack Mountains. The large snowfall totals in southwestern New York on LES days for Lake Ontario likely resulted from coincidental LES activity occurring in association with Lake Erie. This suggests that on Lake Ontario LES days, there were favorable atmospheric and lake conditions supportive of LES systems across a widespread portion of the eastern Great Lakes region. When conditions are supportive of LES over a large area, LES snow bands can develop on an upwind lake, extend over the intervening land area, and continue their development over a downwind lake (e.g., Rodriguez et al., 2007; Laird et al., 2017; Kristovich et al., 2018; Lang et al., 2018).

Snowfall from non-LES days was widespread across the Lake Ontario study region during both cold seasons. The largest snowfall totals occurred in the Catskill Mountains and southern Adirondack Mountains during 2009/2010 (Figure 5B) and over the Tug Hill Plateau and across the entire Adirondack Mountain region during 2012/2013 (Figure 5D). The snowfall totals associated with non-LES days were notably greater than the seasonal totals resulting from LES days. Maximum LWE snowfall totals in both cold seasons from non-LES days approached $40.0 \mathrm{~cm}$. 


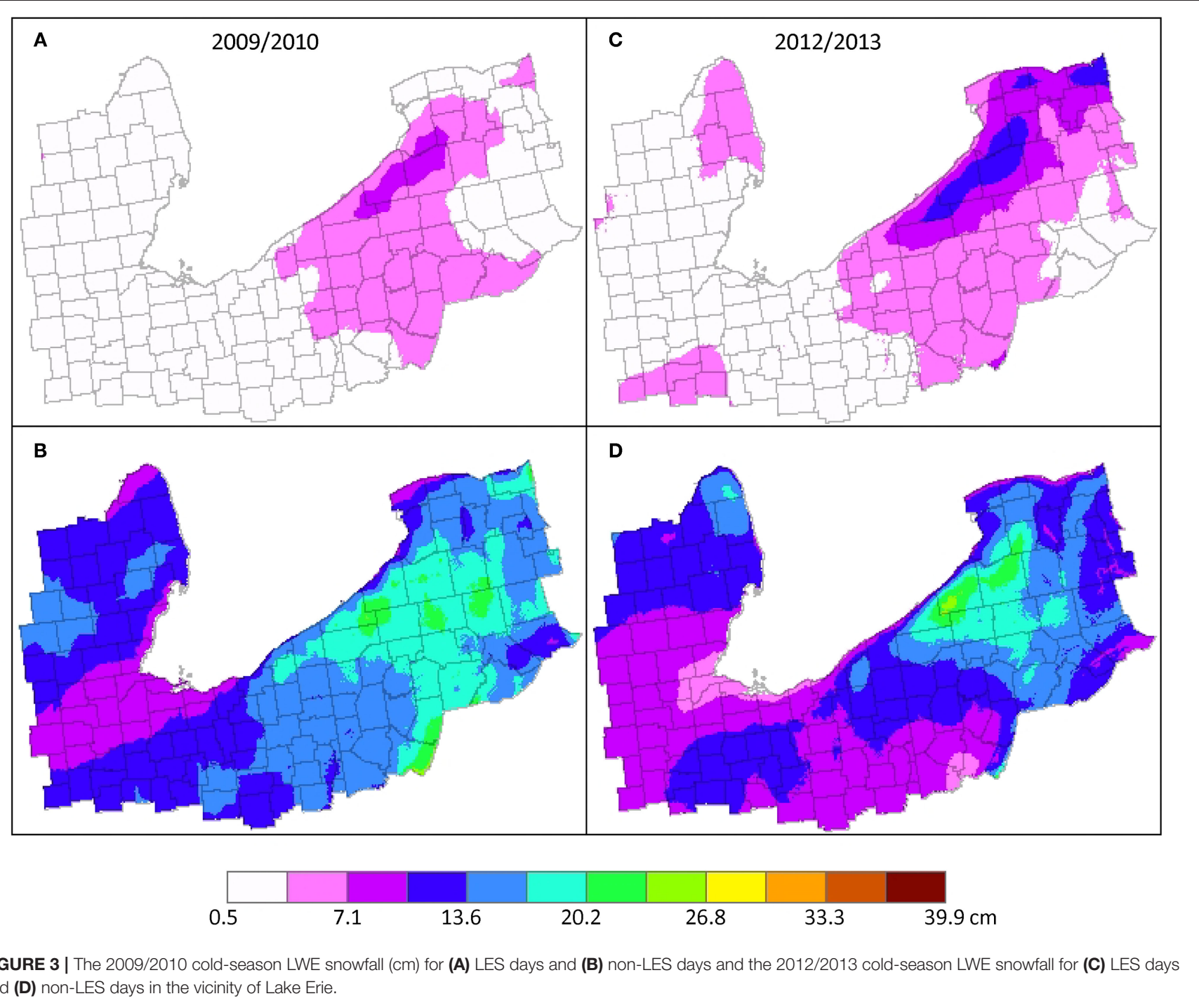

\section{LES Contribution to Total Cold-Season Snowfall Lake Erie}

Snowfall from LES days comprised $20-30 \%$ of total cold-season snowfall in most of the near-shore area southeast of Lake Erie for the 2009/2010 cold season (Figure 6A). A small area located mostly in two counties of western NY (i.e., Erie and Chautauqua) had LES snowfall contributions of $30-40 \%$. Throughout the remainder of the study area, LES snowfall consisted of roughly $10-20 \%$ of total cold-season snowfall. In 2012/2013, LES snowfall comprised a larger percentage of total cold-season snowfall, 30$40 \%$, in the region southeast of Lake Erie and $20-30 \%$ in most other areas (Figure 6D).

\section{Lake Michigan}

East of Lake Michigan LES snowfall comprised $40-70 \%$ of the total cold-season snowfall in 2009/2010 with the maximum percentages occurring near the Traverse Bay region (Figure 6B).
In $2012 / 2013$, these values ranged from 30 to $60 \%$ with maximum percentages occurring to the southeast of Lake Michigan and were slightly less than LES contributions across this region in 2009/2010 (Figure 6E). Since 2012/2013 had a greater number of LES days and higher LES snowfall totals in general, areas with smaller contributions to seasonal totals compared to 2009/2010 might not be expected. Greater LES snowfall contributions to total cold-season snowfall during 2009/2010 demonstrate that the relationship is not directly dependent on the number of LES days during a cold season. For most regions west of Lake Michigan, the contribution of LES snowfall to total coldseason snowfall was between 10 and 20\%, except along the southwestern shoreline near Chicago, IL where LES snowfall comprised $30-40 \%$.

\section{Lake Ontario}

During the two cold seasons, the amount of LES snowfall contributing to the total cold-season snowfall was different in 


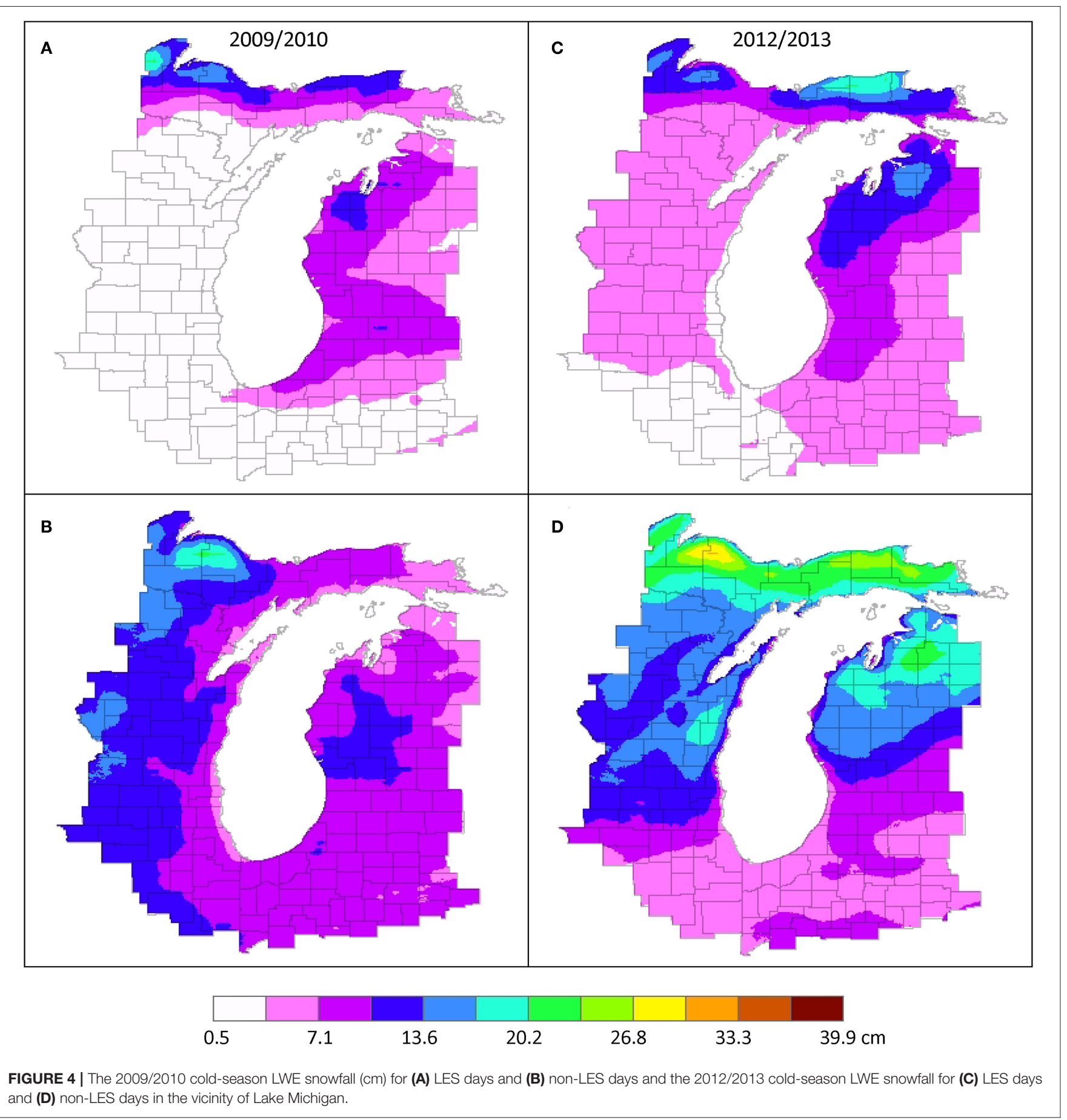

both magnitude and spatial distribution. The maximum LES snowfall contribution in 2009/2010 was located east of Lake Ontario over the Tug Hill Plateau region and had values ranging from 30 to $40 \%$ (Figure 6C). In 2012/2013, the largest LES percentages of total cold-season snowfall ranged from 40 to $50 \%$ and were positioned to the south and southeast of Lake Ontario (Figure 6F). This difference in location of maximum
LES contribution between the two cold seasons may reflect differences in the seasonal mean wind directions during LES days, as well as possible differences in the overall frequency of different types of LES snow bands. The location of the maximum east of Lake Ontario in 2009/2010 suggests greater occurrence of westerly wind directions and long lake-axis parallel snow bands during LES days compared to the location of the 2012/2013 


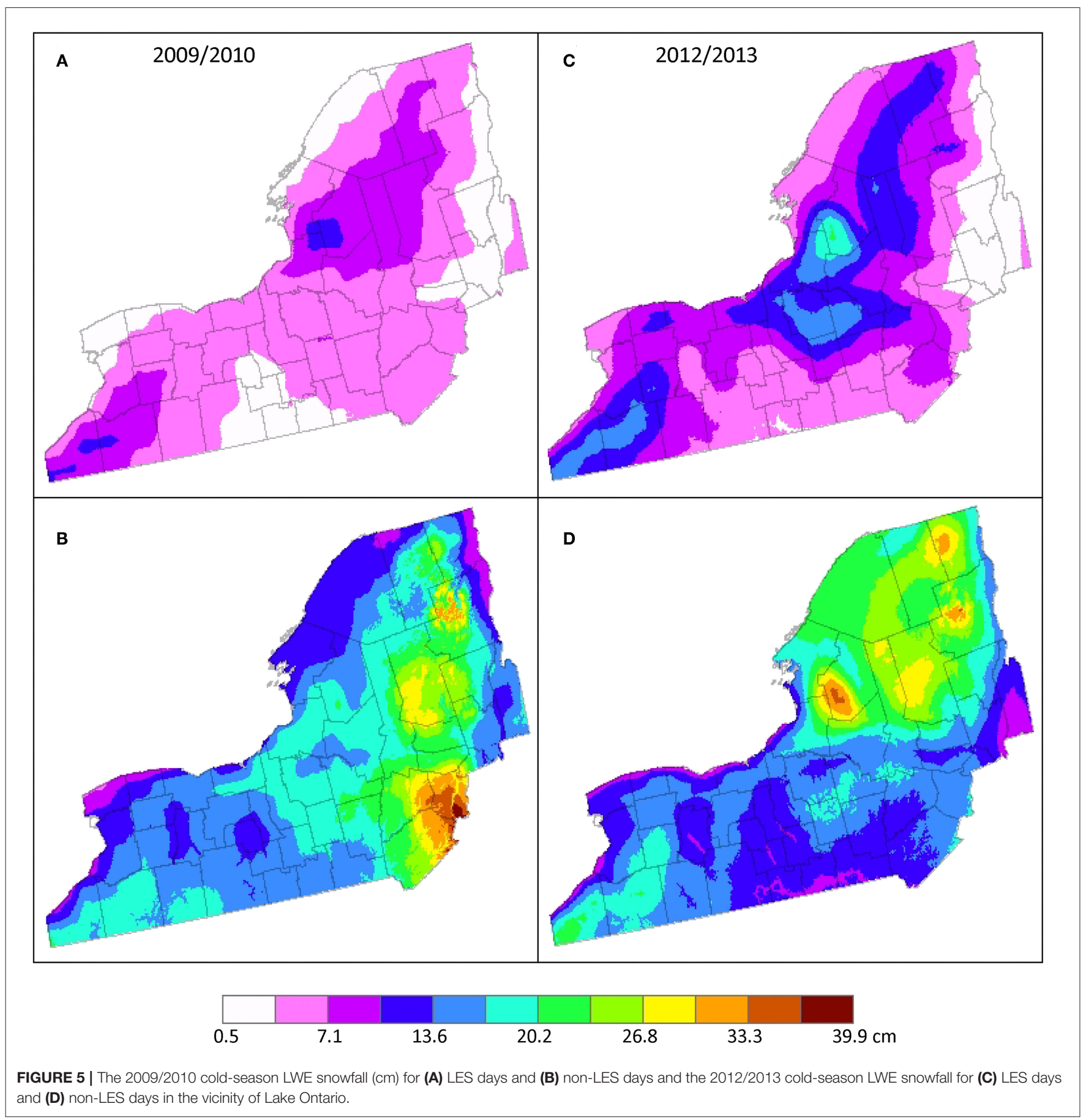

maximum south and southeast of the lake that suggests north or northwesterly wind directions and wind parallel snow bands or LES days with an upwind connection to Lake Huron.

\section{CONCLUSIONS AND DISCUSSION}

A unique approach was taken to determine the LES contribution to total cold-season snowfall. Different from most past LES studies, the current study incorporates information of observed LES occurrences on each lake thereby directly linking snowfall on those days to mesoscale LES clouds and circulations in each lake region. Additionally, the study uses a high-resolution assimilated snowfall dataset that allows for representation of snowfall patterns that are consistent with the mesoscale nature of LES. Two cold seasons were examined with a purposeful choice of seasons differing in the number of LES days. A cold season with the number of LES days notably greater than the mean (i.e., upper 

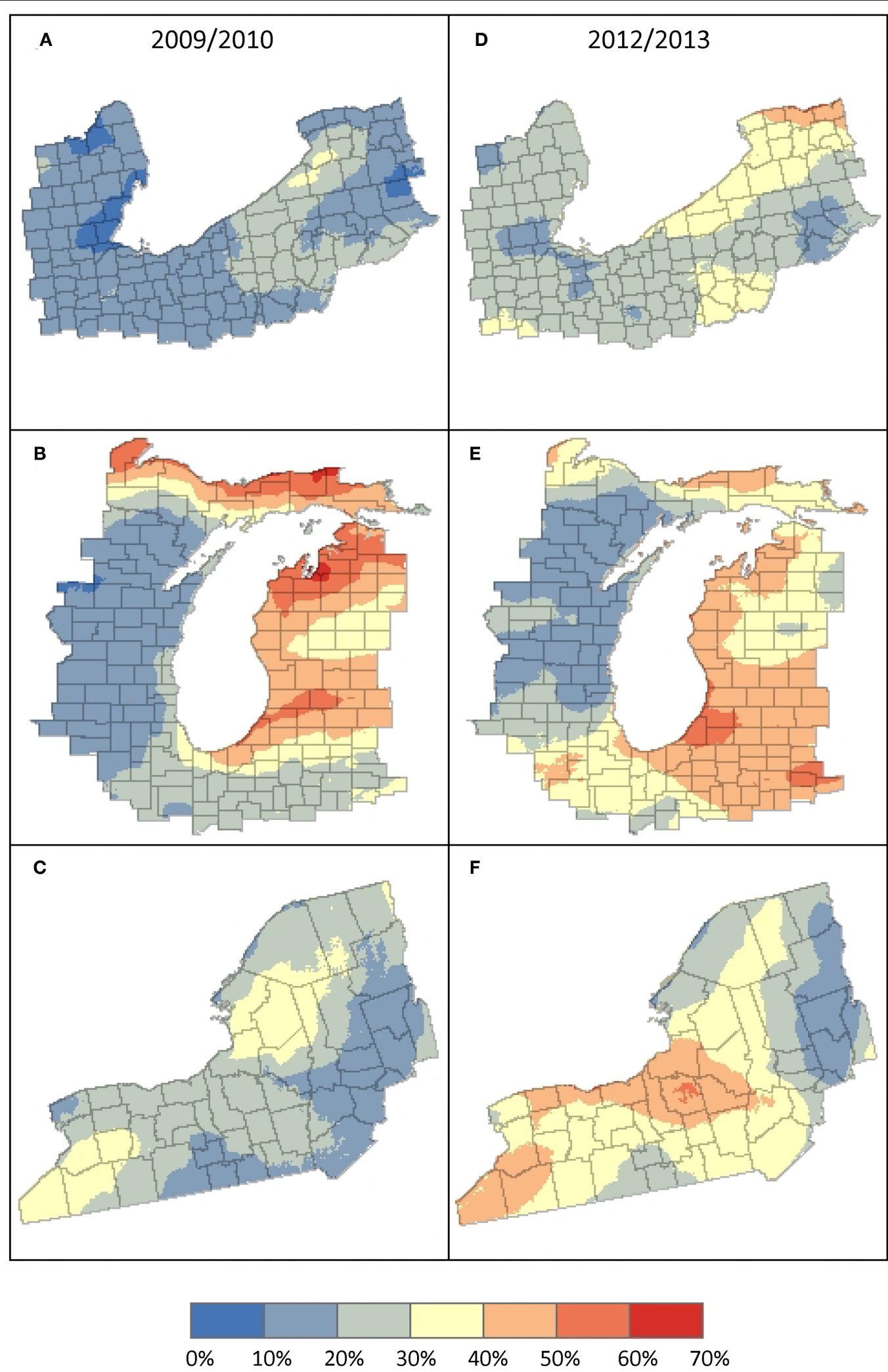

FIGURE 6 | The percentage contribution of LES snowfall (cm) to cold-season snowfall during 2009/2010 for the (A) Lake Erie region, (B) Lake Michigan region, and (C) Lake Ontario region and during 2012/2013 for the (D) Lake Erie region, (E) Lake Michigan region, and (F) Lake Ontario region. 
quartile for all three lakes) and a second cold season with the number of LES days substantially less than the mean (i.e., lowest quartile for all three lakes).

The primary conclusions drawn from the results of this research include:

- LES snowfall contribution to total cold-season snowfall in near-shore areas in the vicinity of Lakes Erie, Michigan, and Ontario do not appear to be directly dependent on the number of LES snowfall days during a cold season. During the two different cold seasons and in different areas surrounding each of the lakes, LES snowfall contributions were found to have a direct, an inverse, or no relationship to the number of cold-season LES days.

- Across the two cold seasons examined, the LES snowfall contribution to total seasonal snowfall ranged from about $10 \%$ to upwards of $70 \%$. The spatial patterns LES snowfall contribution exhibit the mesoscale nature of LES snowstorms with a dependence on atmospheric conditions influencing mean LES snow band position during an individual cold season.

- When comparing the two cold seasons, differences of LES snowfall contributions to total cold-season snowfall for any one location in the vicinity of Lakes Erie, Michigan, and Ontario were as large as $20 \%$ (e.g., southeast of Lake Ontario); however, in most near-shore areas the differences were typically smaller than $10 \%$. Although methodologies differed, this result seems to be consistent with the interannual variation of LES snowfall contribution that Suriano and Wortman (2021) found when examining a larger number of cold seasons. The larger differences in LES snowfall contribution between the two winters investigated in the current study may have resulted from differences of (a) extratropical cyclone frequency and cyclone tracks through the Great Lakes region, (b) the presence and distribution of ice cover on a lake, (c) the variation of snow-to-liquid water content during LES and non-LES snowfall events, and (d) the seasonal mean wind direction. The seasonal mean wind direction would have a direct relation to the mean fetch over a lake during LES atmospheric conditions. This is known to influence the mesoscale structure of the LES snow bands, the likelihood of a multiple lake connection, and the shoreline regions impacted by different LES band types.

- The location of maxima in both LES and non-LES snowfall suggest a notable influence by the terrain in the Great Lakes region, especially in near-shore areas where substantial rise in elevation exists. The enhancement of non-LES snowfall in these areas may suggest an overestimation of LES snowfall contributions to total cold-season snowfall for past approaches that (1) compare measured total cold-season snowfall at locations nearer the lake (i.e., in snowbelt areas) to locations further inland from the lake or (2) compare total coldseason snowfall measured at locations upwind of the lake to downwind locations.

Several recent studies have investigated LES snowfall contribution to winter/cold season snowfall with different
TABLE 2 | LES snowfall contributions to seasonal snowfall for different regions downwind of the Great Lakes reported by recent studies.

\begin{tabular}{lcccc}
\hline & $\begin{array}{c}\text { Lake } \\
\text { Ontario }\end{array}$ & Lake Erie & $\begin{array}{c}\text { Lake } \\
\text { Michigan }\end{array}$ & $\begin{array}{c}\text { Lake } \\
\text { Superior }\end{array}$ \\
\hline $\begin{array}{l}\text { This study: current } \\
\text { study }\end{array}$ & $10-60 \%$ & $10-40 \%$ & $30-70 \%$ & \\
$\begin{array}{l}\text { Veals and } \\
\text { Steenburgh (2015) }\end{array}$ & $\begin{array}{l}61-76 \% \\
\text { Hartnett (2021) }\end{array}$ & & & \\
Suriano and & $40 \%$ & & & \\
Wortman (2021) & $(\sigma-37 \%$ & $48.2 \%$ & & \\
Ellis et al. (2020) & $10-20 \%$ & $10-20 \%$ & $16-32 \%$ & $16-32 \%$ \\
\hline
\end{tabular}

Table cells with gray shading represent contributions reported from LWE and all others represent contributions reported from snowfall depth.

approaches to distinguish LES and non-LES snowfall days for areas downwind of Lake Ontario (Veals and Steenburgh, 2015; Hartnett, 2021), Lakes Erie and Ontario (Suriano and Wortman, 2021), and Lakes Superior, Michigan, Erie and Ontario (Ellis et al., 2020). Each study incorporated different data sets and different time periods, as well as different analysis techniques, so a direct comparison of results is difficult. The data sets used in these studies have incorporated high-resolution spatial data sets, such as satellite or radar, and assimilated snowfall data (current study, Veals and Steenburgh, 2015), examined courser-resolution regional snowfall data sets (Suriano and Wortman, 2021), or analyzed snowfall recorded at individual surface station locations (Ellis et al., 2020; Hartnett, 2021). However, each study offers information directed at the same research question. Table 2 provides summary information about the results from each study for the region(s) included in their investigation.

Future research on this topic should consider examining the interannual and intraseasonal variations of LES snowfall contribution to monthly snowfall totals across multiple decades, as well as investigating how the frequency of LES storm types over a lake may influence the seasonal LES contributions and the location of maxima. High-resolution assimilated snowfall data sets (e.g., SNODAS) seem to capture the local spatial variation of LES snowfall and even the mesoscale variation embedded within widespread snowfall from synoptic systems. The use of these data sets for future studies would likely provide expanded information on the large spatial variation of snowfall and therefore capture the extremes that may exist in spatial variations of LES contributions to seasonal snowfall totals. Snowfall information of this nature would be of great benefit to enhancing understanding of the coldseason hydrology within smaller watersheds across the Great Lakes region.

\section{DATA AVAILABILITY STATEMENT}

The original contributions presented in the study are included in the article/supplementary material, further inquiries can be directed to the corresponding author/s. 


\section{AUTHOR CONTRIBUTIONS}

EJ, CL, and NL contributed to conception, design of the study, and wrote the first draft of the manuscript. EJ and CL organized the database, performed the statistical, and GIS analyses. All authors contributed to manuscript revision, read, and approved the submitted version.

\section{REFERENCES}

Baijnath-Rodino, J. A., Duguay, C. R., and LeDrew, E. (2018). Climatological trends of snowfall over the Laurentian Great Lakes Basin. Int. J. Climatol. 38, 3942-3962. doi: 10.1002/joc.5546

Bard, L., and Kristovich, D. A. (2012). Trend reversal in Lake Michigan contribution to snowfall. J. Appl. Meteorol. Climatol. 51, 2038-2046. doi: 10.1175/JAMC-D-12-064.1

Barrett, A. (2003). National Operational Hydrologic Remote Sensing Center Snow Data Assimilation System (SNODAS) Products at NSIDC. NSIDC Special Report 11. Boulder, CO: National Snow and Ice Data Center, 19.

Braham, R. R., and Dungey, M. J. (1984). Quantitative estimates of the effect of Lake Michigan on snowfall. J. Clim. Appl. Meteorol. 23, 940-949. doi: 10.1175/1520-0450(1984)023<0940:QEOTEO > 2.0.CO;2

Braham, R. R. Jr., and Dungey, M. J. (1995). Lake-effect snowfall over Lake Michigan. J. Appl. Meteor. 34, 1009-1019. doi: 10.1175/1520-0450(1995)034<1009:LESOLM>2.0.CO;2

Burnett, A. W., Kirby, M. E., Mullins, H. T., and Patterson, W. P. (2003). Increasing great Lake-effect snowfall during the twentieth century: a regional response to global warming?. Clim. J. 16, 3535-3542. doi: 10.1175/1520-0442(2003)016<3535:IGLSDT > 2.0.CO;2

Burow, D., and Atkinson, C. (2019). An examination of traffic volume during snow events in northeast Ohio. Nat. Hazards 99, 1179-1189. doi: 10.1007/s11069-019-03786-y

Clark, C. A., Elless, T. J., Lyza, A. W., Ganesh-Babu, B., Koning, D. M., Carne, A. R., et al. (2016). Spatiotemporal snowfall variability in the Lake Michigan region: how is warming affecting wintertime snowfall?. J. Appl. Meteorol. Climatol. 55, 1813-1830. doi: 10.1175/JAMC-D-15-0285.1

Clark, C. A., Ganesh-Babu, B., Elless, T. J., Lyza, A. W., Koning, D. M., Carne, A. R., et al. (2018). Spatio-temporal November and March snowfall trends in the Lake Michigan region. Int. J. Climatol. 38, 3250-3263. doi: 10.1002/joc.5498

Dewey, K. F. (1970). An analysis of lake-effect snowfall. Bull. III. Geogr. Soc. $12,27-42$.

Eichenlaub, V. L. (1970). Lake effect snowfall to the lee of the Great Lakes: its role in Michigan. Bull. Am. Meteorol. Soc. 51, 402-412. doi: 10.1175/1520-0477(1970)051<0403:LESTTL>2.0.CO;2

Ellis, A. W., and Johnson, J. J. (2004). Hydroclimatic analysis of snowfall trends associated with the north American Great Lakes. J. Hydrometeorol. 5, 471-486. doi: 10.1175/1525-7541(2004)005<0471:HAOSTA > 2.0.CO;2

Ellis, A. W., Marston, M. L., and Bahret, J. B. (2020). Changes in the frequency of cool season lake effects within the north American Great Lakes Region. Ann. Am. Assoc. Geogr. 111, 385-401. doi: 10.1080/24694452.2020. 1785270

Hartnett, J. J. (2021). A classification scheme for identifying snowstorms affecting central New York State. Int. J. Climatol. 41, 1712-1730. doi: 10.1002/joc.6922

Hartnett, J. J., Collins, J. M., Baxter, M. A., and Chambers, D. P. (2014). Spatiotemporal snowfall trends in Central New York. J. Appl. Meteorol. Climatol. 53, 2685-2697. doi: 10.1175/JAMC-D-14-0084.1

Jiusto, J., and Kaplan, M. (1972). Snowfall from lake-effect storms. Mon. Weather Rev. 100, 62-66. doi: 10.1175/1520-0493(1972)100<0062:SFLS $>2.3 . C O ; 2$

Kelly, R. D. (1986). Mesoscale frequencies and seasonal snowfalls for different types of Lake Michigan snow storms. J. Appl. Meteorol. 25, 308-312. doi: 10.1175/1520-0450(1986)025<0308:MFASSF > 2.0.CO;2

Kristovich, D. A., Bard, L., Stoecker, L., and Geerts, B. (2018). Influence of Lake Erie on a Lake Ontario lake-effect snowstorm. J. Appl. Meteorol. Climatol. 57, 2019-2033. doi: 10.1175/JAMC-D-17-0349.1

\section{FUNDING}

This research was primarily conducted during the 2016, 2017, and 2021 Undergraduate Summer Research Programs at Hobart and William Smith (HWS) Colleges and supported by the National Science Foundation Research awards AGS-1258548, AGS-2040594, and the HWS Provost's Office.

Kunkel, K. E., Ensor, L., Palecki, M., Easterling, D., Robinson, D., Hubbard, K. G., et al. (2009). A new look at lake-effect snowfall trends in the Laurentian Great Lakes using a temporally homogeneous data set. J. Great Lakes Res. 35, 23-29. doi: 10.1016/j.jglr.2008.11.003

Laird, N. F., Metz, N., Gaudet, L., Grasmick, C., Higgins, L., Loeser, C., et al. (2017). Climatology of cold season lake-effect cloud bands for the North American Great Lakes. Int. J. Climatol. 37, 2111-2121. doi: 10.1002/joc. 4838

Lang, C. E., McDonald, J. M., Gaudet, L., Doeblin, D., Jones, E. A., and Laird, N. F. (2018). The influence of a Lake-to-Lake connection from Lake Huron on the lake-effect snowfall in the vicinity of Lake Ontario. J. Appl. Meteorol. Climatol. 57, 1423-1439. doi: 10.1175/JAMC-D-17-0225.1

Muller, R. (1966). Snowbelts of the Great Lakes. Weatherwise 19, 248-257. doi: 10.1080/00431672.1966.10544204

Norton, D. C., and Bolsenga, S. J. (1993). Spatiotemporal trends in lake effect and continental snowfall in the Laurentian Great Lakes, 1951-1980. Clim. J. 6, 1943-1956. doi: 10.1175/1520-0442(1993)006<1943:STILEA > 2.0.CO;2

Owens, N. D., Rauber, R. M., Jewett, B. F., and McFarquhar, G. M. (2017). The contribution of lake enhancement to extreme snowfall within the chicago-milwaukee urban corridor during the 2011 groundhog day blizzard. Mon. Weather Rev. 145, 2405-2420. doi: 10.1175/MWR-D-170025.1

Rodriguez, Y., Kristovich, D. A., and Hjelmfelt, M. R. (2007). Lake-to-Lake cloud bands: frequencies and locations. Mon. Weather Rev. 135, 4202-4213. doi: 10.1175/2007MWR1960.1

Schmidlin, T. W. (1993). Impacts of severe winter weather during december 1989 in the lake erie snowbelt. J. Clim. 6, 759-767. doi: 10.1175/1520-0442 (1993)006

Scott, R. W., and Huff, F. A. (1996). Impacts of the Great Lakes on regional climate conditions. J. Great Lakes Res. 22, 845-863. doi: 10.1016/S0380-1330(96) 71006-7

Strommen, N. D., and Harman, J. R. (1978). Seasonally changing patterns of lake-effect snowfall in western lower Michigan. Mon. Weather Rev. 106, 503-509. doi: 10.1175/1520-0493(1978)106<0503:SCPOLE > 2.0.CO;2

Suriano, Z. J. (2019). Changing intrasynoptic type characteristics and interannual frequencies of circulation patterns conducive to lake-effect snowfall. J. Appl. Meteorol. Climatol. 58, 2313-2328. doi: 10.1175/JAMC-D-190069.1

Suriano, Z. J., and Leathers, D. J. (2017). Synoptically classified lake-effect snowfall trends to the lee of Lakes Erie and Ontario. Clim. Res. 74, 1-13. doi: $10.3354 / \mathrm{cr} 01480$

Suriano, Z. J., Leathers, D. J., Hall, D. K., and Frei, A. (2019). Contribution of snowfall from diverse synoptic conditions in the Catskill/Delaware Watershed of New York State. Int. J. Climatol. 39, 3608-3618. doi: 10.1002/joc. 6043

Suriano, Z. J., and Wortman, R. D. (2021). Temporal trends in snowfall contribution induced by lake-effect synoptic types. Phys. Geogr. 42, 416-433. doi: 10.1080/02723646.2020.1792048

Veals, P. G., and Steenburgh, W. J. (2015). Climatological characteristics and orographic enhancement of lake-effect precipitation east of Lake Ontario and over the Tug Hill Plateau. Mon. Weather Rev. 143, 3591-3609. doi: 10.1175/MWR-D-15-0009.1

Wilson, J. W. (1977). Effect of Lake Ontario on precipitation. Mon. Weather Rev. 105, 207-214. doi: 10.1175/1520-0493(1977)105<0207:EOLOOP $>2.0 . \mathrm{CO} ; 2$ 
Yeager, K. N., Steenburgh, W. J., and Alcott, T. I. (2013). Contributions of Lakeeffect periods to the cool-season hydroclimate of the great salt lake basin. J. Appl. Meteor. Climatol. 52, 341-336. doi: 10.1175/JAMC-D-12-077.1

Conflict of Interest: The authors declare that the research was conducted in the absence of any commercial or financial relationships that could be construed as a potential conflict of interest.

Publisher's Note: All claims expressed in this article are solely those of the authors and do not necessarily represent those of their affiliated organizations, or those of the publisher, the editors and the reviewers. Any product that may be evaluated in this article, or claim that may be made by its manufacturer, is not guaranteed or endorsed by the publisher.

Copyright (C) 2022 Jones, Lang and Laird. This is an open-access article distributed under the terms of the Creative Commons Attribution License (CC BY). The use, distribution or reproduction in other forums is permitted, provided the original author(s) and the copyright owner(s) are credited and that the original publication in this journal is cited, in accordance with accepted academic practice. No use, distribution or reproduction is permitted which does not comply with these terms. 